\title{
Annual sediment primary production and respiration in a large coral reef lagoon (SW New Caledonia)
}

\author{
Jacques Clavier $^{1, *}$, Claire Garrigue $^{2}$ \\ ${ }^{1}$ Institut de Recherche pour le Développement, Centre de Bretagne, BP 70, 29280 Plouzané, France \\ ${ }^{2}$ Institut de Recherche pour le Développement, Centre de Nouméa, BP A5, 98848 Nouméa, New Caledonia
}

\begin{abstract}
Sediment photosynthetic production and community respiration were investigated for 1 yr in the south-west lagoon of New Caledonia (surface area: $2000 \mathrm{~km}^{2}$; mean depth: $21 \mathrm{~m}$ ). Metabolic fluxes were measured at the water-sediment interface using benthic enclosures, at 60 sampling stations randomly distributed in space and time. Mean gross primary production $\left(P_{\mathrm{g}}\right)$ was $12.06 \mathrm{~mol} \mathrm{C} \mathrm{m}^{-2} \mathrm{yr}^{-1}$

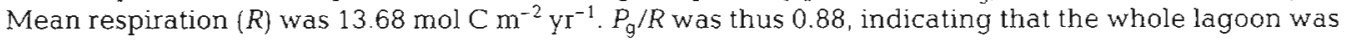
net heterotrophic. There were, however, large differences along a land-ocean gradient. Muddy bottoms ( $35 \%$ of the lagoon surface), located along the shore and in the deeper part of the lagoon, were significantly heterotrophic $\left(P_{\mathrm{g}} / R=0.39\right)$, whereas the ratio for sandy bottoms ( $65 \%$ of the area) towards the reef were close to 1 or slightly positive, indicating potentially autotrophic benthic communities. Both $P_{\mathrm{g}}$ and $R$ followed a similar seasonal variation with higher values during the warm season (November to February), when maximum irradiance and the particulate organic carbon supply occurred. These results suggest that autotrophy, generally observed in coral reef flats, may also occur in lagoon sediments, indicating both a major importance of regeneration processes and a relative equilibrium of energy exchanges with adjacent ecosystems. Terrestrial influence results in a decrease of autochthonous production and a correlative increase of carbon sedimentation leading to benthic heterotrophy.
\end{abstract}

KEY WORDS: Coral reef lagoon - Benthic community metabolism · Sediments

\section{INTRODUCTION}

Most of our knowledge of coral reef ecosystems is about the reef compartment (Kinsey 1985a, Dubinsky 1990, Sorokin 1993). Community gross primary production of coral reefs is high, with a mean value of $\mathrm{ca}$ $0.6 \mathrm{~mol} \mathrm{C} \mathrm{m} \mathrm{m}^{-2} \mathrm{~d}^{-1}$ (Kinsey 1985a); respiration is of the same order of magnitude and the budget of organic carbon is considered to be balanced (Crossland et al. 1991) or slightly positive (Gattuso et al. 1993, Smith 1995). Energy transfer from reef to the adjacent lagoon

\footnotetext{
- Present address: Institut Universitaire Européen de la Mer, UMR 6539, Technopole Brest Iroise, Place Nicolas Copernic, 29280 Plouzané, France.

E-mail: jacques.clavier@univ-brest.fr
}

is thus necessarily low. Along islands or continental coasts, mangroves can supply organic carbon for surrounding communities, but their importance seems to be overrated because of the refractory nature of the exported organic matter and its low energetic value (Alongi \& Christoffersen 1992). Thus, the functioning of the large sedimentary areas often observed in coral reef environments are still poorly understood (Gattuso et al. 1998) It is generally considered, however, that sediment respiration exceeds global production in terms of carbon (Yap et al. 1994). Sediment is thus regarded as a carbon sink for reef excess production or other energy sources.

The lagoons surrounding the mainland of New Caledonia (SW Pacific) cover a $24000 \mathrm{~km}^{2}$ area delimited by a $1600 \mathrm{~km}$ long barrier reef (Richer de Forges 1991). These coastal lagoons are under the influence of ter- 
restrial input unlike atoll lagoons. The south-west lagoon surrounding Nouméa peninsula was selected for an energy flux study. Previous studies on this site have investigated the biomass of functional compartments (Chardy \& Clavier 1988a, Garrigue 1995, 1998), the vertical flux of particulate matter (Clavier et al. 1995) and sediment community metabolism (Boucher \& Clavier 1990, Boucher et al. 1994a). A first attempt to estimate the carbon network was made by Chardy \& Clavier (1988b) with energy flows mainly derived from the literature. Two benthic energy sources were defined: the known vertical flux of organic particles (Clavier et al. 1995) and the unknown autochthonous photosynthetic production.

The aims of the present study were: (1) to evaluate, for the whole lagoon, the annual contribution of benthic primary production in the supply of carbon for benthic respiration, (2) to estimate the balance between benthic production and respiration in the different benthic communities in order to establish their relative importance in the metabolic status of the lagoon, and, (3) to determine seasonal changes in the metabolism of soft-bottom communities relative to physical factors.

\section{MATERIAL AND METHODS}

Study site. The south-west lagoon of New Caledonia covers $2066 \mathrm{~km}^{2}, 5 \%$ of which is occupied by coral reef structures. The average depth is $21 \mathrm{~m}$. Three main softbottom types have been identified (Fig. 1): the mud deposits near the coast and in the deeper parts, the grey sand bottoms in the middle, and the white sand battoms close to the reef. They make up 35, 50 and $15 \%$ of the lagoon surface, respectively. The classification was established for macrobenthic assemblages related to sediment granulometry (Chardy \& Clavier 1988a, Chardy et al. 1988) and validated with other benthic parameters, especially aerobic and anaerobic metabolism (Boucher \& Clavier 1990, Boucher et al. 1994a). This general distribution was refined using macrophyte association by Garrigue (1995).

Sampling strategy. Benthic fluxes at the water-sediment interface were estimated from photosynthetic production and respiration. Benthic metabolism, first linked to benthic biological activity, and hence community composition (Pichon 1997), is controlled through the physiology of plants and animals by environmental physico-chemical parameters (light, depth, substrate, turbidity, temperature), which can vary in space as well as in time. A spatio-temporal sampling was thus applied to the soft bottoms of the whole lagoon from July 1990 to June 1991. The following assumptions were used: (1) photosynthetic production only occurs between sunrise and sunset, (2) any fluctuation of photosynthetic production can be related to the time during the day, the period of the year and the location in the lagoon, (3) community respiration does not change during a $24 \mathrm{~h}$ cycle and only varies according to the season and the location in the lagoon.

The soft bottoms of the lagoon during 1 yr constitute the sampled statistic population. The day was divided into $1 \mathrm{~h}$ periods corresponding to the planned duration of production experiments. The months of the year were divided into 6 groups to take into account the seasonal fluctuations of light, temperature and day duration, and the technical limitations of the field work (availability of facilities at sea, diving and meteorological limitations, etc.). Geographical localisation of the
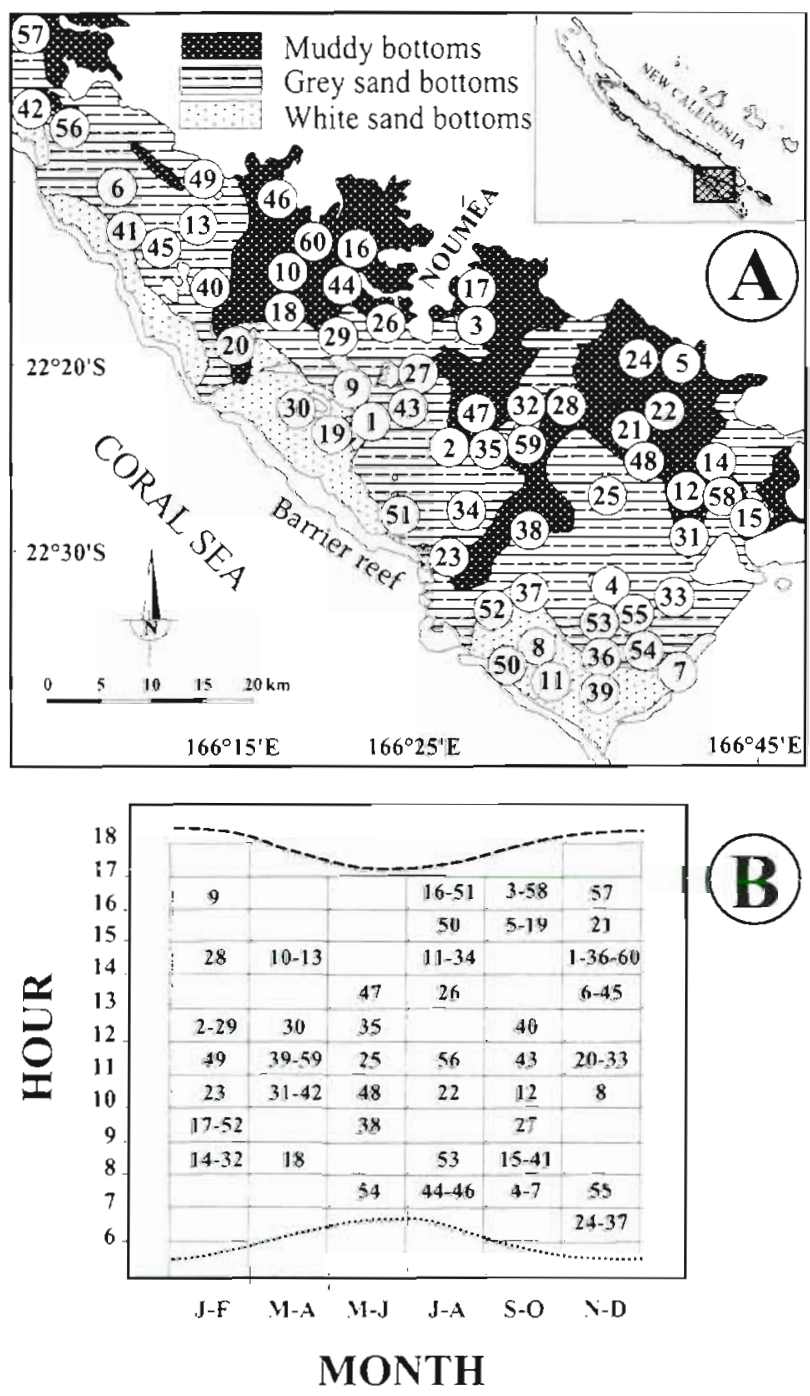

Fig. 1 Distribution of sampling stations in (A) space and (B) time. Dotted lines in $B$ indicate seasonal cycle of sunrise and sunset 
sampling sites was defined in the lagoon with a 0.1 nautical mile precision both in latitude and in longitude. The sampling unit consisted of three $0.2 \mathrm{~m}^{2}$ areas over $1 \mathrm{~h}$. It was defined by 4 co-ordinates: latitude, longitude, month and hour of the day. The total number of samples was set to 60 because of the time at our disposal. There was not enough information on benthic photosynthetic production in the lagoon to allow stratified sampling. Accordingly, the 4 co-ordinates of each station were randomly drawn (Fig. 1). This sampling was regarded as a simple random sampling (Cochran 1977). However, we can only obtain an approximation, because we studied three $0.2 \mathrm{~m}^{2}$ and $1 \mathrm{~h}$ sub-samples by $0.1 \times 0.1$ nautical mile and 2 mo sampling unit. The number of stations by bottom type allocated by the random sampling over the whole lagoon was 21 in mud deposits, 27 in grey sand bottoms and 12 in white sand bottoms.

Incubation procedure. Incubations were carried out from the RV 'Alis'. At each station, community primary production and respiration were obtained from changes in dissolved oxygen measured in three $60 \mathrm{l}$ clear acrylic hemispheres fastened to $0.2 \mathrm{~m}^{2}$ PVC bases (Boucher \& Boucher-Rodoni 1985, 1988, Boucher et al. $1994 \mathrm{a}, \mathrm{b})$. Water motion was provided by adjustable submersible pumps connected to waterproof batteries. Oxygen concentrations were measured with the polarographic probes of 3 Yellow Spring Instrument (YSI 58) oxymeters refitted in a waterproof container and connected to a data logger. Oxygen concentrations and saturation rates could be checked underwater on liquid crystal displays. As metabolic response depends on hydrodynamics (Patterson et al. 1991, Forja \& Gómez-Parra 1998), water flow in each enclosure was adjusted to the minimum value allowing stable measures from the probes. A quantum sensor (LI-192SA) was deployed inside one of the hemispheres to measure the photosynthetically active radiation (PAR, 400 to $700 \mathrm{~nm}$ ) available for the enclosed plants. Oxygen concentrations and irradiance were logged every $5 \mathrm{~s}$.

After a $30 \mathrm{~min}$ waiting period to lessen the disturbance created by experimental material setting, incubations were first carried out in light for $1 \mathrm{~h}$ to estimate the net oxygen photosynthetic production. Photosynthetic processes were then inhibited by injecting DCMU (final concentration of $5 \times 10^{-5} \mathrm{~mol} \mathrm{l}^{-1}$ ), a photosynthesis inhibitor that is easy to handle in severe diving conditions and simulates dark incubation (Garrigue et al. 1992a). As oxygen tension could influence production (Dromgoole 1978), enclosed water was flushed prior to DCMU injection when the oxygen saturation rate exceeded $110 \%$. Logging was resumed, for $1 \mathrm{~h}$, after a period of 15 min to ensure that photosynthesis was fully inhibited.
The enclosed macroflora was collected by hand upon completion of the incubations. Thee $5.31 \mathrm{~cm}^{2}$ cores were taken in each enclosure to estimate photosynthetic pigments from the top $\mathrm{cm}$ of substrate. About $100 \mathrm{~g}$ of sediment was also collected for granulometric analysis.

Processing of the samples. The sediment samples were deep frozen pending analysis. Data were downloaded to a computer. Irradiance $\left(I, \mathrm{mmol} \mathrm{m} \mathrm{m}^{-2} \mathrm{~h}^{-1}\right)$ was integrated over the incubation hour and oxygen concentrations were averaged every minute. Net hourly photosynthetic production $\left(P_{n}\right)$ was calculated as the difference between concentrations at the beginning and at the end of incubations carried out in light, after checking the regularity of the data. Total sediment oxygen consumption was computed by linear regression of the 60 mean values acquired after DCMU injection. To obtain only the benthic respiration of the enclosed system $(R)$, total sediment oxygen consumption was adjusted for oxygen demand of the apparatus without sediment. The latter, assessed from 12 in situ isolated water dark incubations, was $0.810^{-3} \mathrm{mmol} \mathrm{O}_{2} \mathrm{l}^{-1} \mathrm{~h}^{-1}$ $\left(\mathrm{SE}=0.1 \times 10^{-3}\right)$. Gross primary production $\left(P_{\mathrm{g}}\right)$ was estimated as $P_{n}$ corrected from total sediment oxygen consumption. Net planktonic photosynthetic production of the enclosed water, very close to 0 , was considered to be negligible compared to the benthic production. Oxygen fluxes were transformed to carbon fluxes using benthic community metabolic quotients calculated from the same area at different sites and seasons (Clavier et al. 1994): 1.03 for the community photosynthetic quotient $\left(\mathrm{CPQ}=\right.$ gross $\mathrm{O}_{2}$ production/gross $\mathrm{CO}_{2}$ consumption) and 1.14 for the community respiratory quotient $\left(\mathrm{CRQ}=\mathrm{CO}_{2}\right.$ production $/ \mathrm{O}_{2}$ consumption).

In the laboratory, macrophyte ash-free dry weight (AFDW) was measured after drying at $60^{\circ} \mathrm{C}$ for $48 \mathrm{~h}$ and oven heating at $550^{\circ} \mathrm{C}$ for $3 \mathrm{~h}$. Photosynthetic pigments were estimated on lyophilised sediment samples after acetone extraction for 18 to $24 \mathrm{~h}$ at $5^{\circ} \mathrm{C}$. After filtration of the extract, optical densities were measured on a spectrophotometer at 750 and $665 \mathrm{~nm}$ (Garrigue \& Di Matteo 1991). Chlorophyll a (chl a) and phaeopigments were calculated as described by Lorenzen (1967). Sediment particle size fractions were determined according to Folk \& Ward (1957).

Statistical treatment of data and modelling. ANOVAs were performed to test spatial and temporal homogeneity of the parameters under study. Normality of data (Shapiro and Wilk test) and homogeneity of variances (Bartlett test) were verified prior to analysis. The least significant difference (LSD) test was used to separate possible sets of homogeneous data (Sokal \& Rohlf 1981). The $P_{\mathrm{g}} / R$ ratio and its confidence limits were calculated according to Cochran (1977) for a simple random sampling. 
Gross primary production is essentially determined by the amount of plant material and irradiance. Gross primary production in carbon was plotted as a function of in situ irradiance. An exponential function (Gattuso et al. 1996, Boucher et al. 1998) was fitted to the community productivity:

$$
P_{g}=P_{g \max }\left[1-\exp \left(-I / I_{k}\right)\right]+e
$$

where $P_{\mathrm{g}}$ : gross primary production; $P_{\mathrm{g} \max }$ : rate of maximum gross productivity; $I$ : irradiance; $I_{k}$ : the optimum irradiance, where $P_{\mathrm{g}}=P_{\mathrm{g} \text { max }}$ and $e$ : a constant. Gross primary production was also related to macrophyte (AFDW) and microphyte (chl a) biomass using linear relationships.

The relation between gross primary production and the 3 pooled variables was then expressed as:

$$
P_{\mathrm{g}}=P_{\mathrm{g} \max }\left[1-\exp \left(-I / I_{k}\right)\right]+a \mathrm{AFDW}+b \mathrm{chl} a+c
$$

where $c$ : a constant; and $a$ and $b$ : multiplicative factors Non-linear estimation was computed using leastsquare estimates (Simplex procedure).

\section{RESULTS}

A detailed account of the raw data for each station is found in the report by Garrigue et al. (1992b).

\section{Environmental parameters}

Water temperature varied from 22.3 to $28.1^{\circ} \mathrm{C}$, with an average of $24.3^{\circ} \mathrm{C}$. The mean irradiance inside the enclosures was $204 \mathrm{mmol} \mathrm{m}^{-2} \mathrm{~h}^{-1}$ and the maximal value was $791 \mathrm{mmol} \mathrm{m}^{-2} \mathrm{~h}^{-1}$. Monthly courses of both temperature and irradiance are shown in Fig. 2. They exhibit a seasonal pattern with extreme values of irradiance occurring before highest temperatures. The maximal irradiance observed in the September-October results, however, was the major contribution of 1 shallow station. The mean irradiance for the period

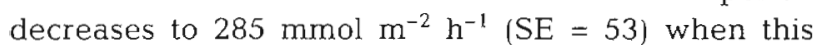
value is removed. The mean depth and sedimentological characteristics of the stations sampled in each bottom type are indicated in Table 1. Depth and mud percentage were significantly different for the 3 types of sediment (ANOVA, $\mathrm{p}<0.05$ ), but only mud deposits were characterised by significantly higher mean size in phi scale corresponding to fine sand on the Wentworth (1922) scale. Other lagoon sediments corresponded to medium sand. Phaeopigment and chl a percentage (Table 2) differed significantly for the 3 bottom types (ANOVA, p < 0.05). Mud deposits were characterised by a significantly lower chl a content, whereas grey sand bottoms exhibited the highest macroflora biomass

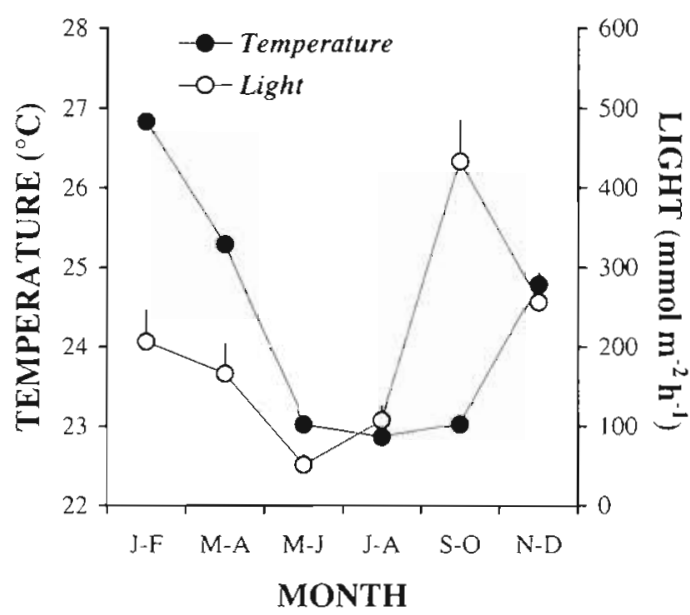

Fig. 2. Seasonal cycle of temperature and light in the lagoon Vertical bars correspond to the standard errors

Table 1. Mean values (SE are in parentheses) of sediment characteristics. \% Md: \% of particles $<63 \mu \mathrm{m}$ in the sediment; MS: phi-value of the grain mean size

\begin{tabular}{|lccc|}
\hline & Depth $(\mathrm{m})$ & $\% \mathrm{Md}$ & $\mathrm{MS}$ \\
\hline Mud deposits & $25.6(0.8)$ & $46.0(3.0)$ & $2.7(0.1)$ \\
Grey sand bottoms & $20.4(0.6)$ & $12.1(0.8)$ & $1.6(0.1)$ \\
White sand bottoms & $14.4(0.7)$ & $4.1(0.4)$ & $1.5(0.1)$ \\
Whole lagoon & $21.0(0.5)$ & $22.31 .7)$ & $2.0(0.1)$ \\
\hline
\end{tabular}

(Table 2). Phaeopigments were lowest in July-August and highest in November-December. Macroflora biomass, chl a and the contribution of chl a to total pigments did not differ significantly over the year, except for the January-February highest values. For macroflora, this feature was due to the sampling during this period of a very dense Halodule uniñervis seagrass bed at Stn 14. The January-February mean macroflora biomass would decrease to $13 \mathrm{~g} \mathrm{AFDW} \mathrm{m}^{-2}$ if this station was removed from the analysis.

\section{Gross photosynthetic production}

The mean benthic community gross photosynthetic production in oxygen estimated from the whole data set was $2.83 \mathrm{mmol} \mathrm{m}^{-2} \mathrm{~h}^{-1}(\mathrm{SE}=0.23)$, corresponding to a calculated carbon flux of $2.75 \mathrm{mmol} \mathrm{m}^{-2} \mathrm{~h}^{-1}$. With an annual mean of $12 \mathrm{~h} 02 \mathrm{~min}$ daylight per day in southern New Caledonia, the mean $P_{\mathrm{g}}$ was $33.03 \mathrm{mmol} \mathrm{C} \mathrm{m} \mathrm{Cd}^{-1}(\mathrm{SE}=2.67)$ and the mean annual value was $12.06 \mathrm{~mol} \mathrm{C} \mathrm{m} \mathrm{Cr}^{-2}$. For the whole lagoon, the total annual $P_{\mathrm{g}}$ in carbon was $2.38 \times 10^{10} \mathrm{~mol} \mathrm{C} \mathrm{yr}^{-1}$ 
Table 2. Mean benthic biomasses (SE are in parentheses) in different bottom types over the year. chl a: chlorophyll a (mg $\left.\mathrm{m}^{-2}\right)_{i}$ Phaeo: phaeopigments $\left(\mathrm{mg} \mathrm{m} \mathrm{m}^{-2}\right) ; \% \mathrm{chl}$ a: percentage of chl $a$ in total pigments; Macroflora: macroflora biomass as ash free dry weight $\left(\mathrm{g} \mathrm{m}^{-2}\right)$. Chl $a$ and phaeo refer to the top centimetre of sediment

\begin{tabular}{|llllrr|} 
& Chl a & Phaeo $\%$ chl a & \multicolumn{1}{c|}{$\begin{array}{c}\text { Macro- } \\
\text { flora }\end{array}$} \\
\hline Bottom type & & & & & \\
Mud deposits & $23(1)$ & $79(2)$ & $22(1)$ & $0.78(0.21)$ \\
Grey sand bottoms & $59(4)$ & $64(2)$ & $46(1)$ & $19.88(3.33)$ \\
White sand bottoms & $62(5)$ & $42(3)$ & $58(1)$ & $5.04(1.20)$ \\
Whole lagoon & $47(2)$ & $65(2)$ & $40(1)$ & $10.23(1.65)$ \\
Month & & & & \\
January-February & $77(10)$ & $62(3)$ & $51(3)$ & $27.61(8.58)$ \\
March-April & $37(4)$ & $68(5)$ & $36(3)$ & $2.62(0.77)$ \\
May-June & $38(5)$ & $69(4)$ & $33(3)$ & $5.00(1.39)$ \\
July-August & $36(4)$ & $53(4)$ & $40(3)$ & $4.14(1.58)$ \\
September-October & $44(4)$ & $74(4)$ & $36(2)$ & $11.02(2.42)$ \\
November-December & $47(4)$ & $62(3)$ & $42(3)$ & $8.66(1.55)$ \\
& & & & \\
\hline
\end{tabular}

$\left(\mathrm{SE}=0.13 \times 10^{10}\right)$. ANOVA demonstrated that no significant difference could be detected within the 3 replicate enclosures $(\mathrm{p}=0.39)$, but $P_{\mathrm{g}}$ was significantly different in the 3 bottom types ( $p<0.001)$. Gross primary production was similar in the grey sand and white sand bottoms and significantly lower in muddy bottoms (Table 3). The evolution of $P_{\mathrm{g}}$ during the daylight period was significant $(\mathrm{p}<0.001)$ and showed a classical diurnal pattern with minimal values at the beginning and at the end of the day, and a maximum at midday (Fig. 3). The yearly evolution (Fig. 4) also exhibited a significant cycle (ANOVA, $p<0.001$ ) with minimal values during the cool season (from May to August) and significantly higher values during the warm season (from November to February).

\section{Benthic respiration}

The mean benthic community respiration in oxygen was $1.37 \mathrm{mmol} \mathrm{m}^{-2} \mathrm{~h}^{-1}(\mathrm{SE}=0.10)$ and the carbon

Table 3. Mean values of metabolic parameters in the 3 bottom types of the lagoon. $P_{\mathrm{g}}$ : gross photosynthetic production $\left(\mathrm{mmol} \mathrm{C} \mathrm{m} \mathrm{C}^{-2} \mathrm{~d}^{-1}\right)$; $R$ : respiration of the benthos $\left(\operatorname{mmol~C~m} \mathrm{m}^{-2} \mathrm{~d}^{-1}\right)$; $P_{\mathrm{g}} / R$ : production/respiration ratio. Standard errors for $P_{\mathrm{g}} R$ and $95 \%$ confidence limits for their ratios are in parentheses

\begin{tabular}{|lrcc|}
\hline Bottom & $P_{g}$ & $R$ & $P_{\mathrm{g}} / R$ \\
\hline Mud deposits & $7.72(1.66)$ & $19.55(0.96)$ & $0.39(0.07-0.72)$ \\
Grey sand & $44.96(4.47)$ & $47.67(3.48)$ & $0.94(0.60-1.28)$ \\
White sand & $49.85(4.45)$ & $45.47(3.86)$ & $1.10(0.63-1.54)$ \\
\hline
\end{tabular}

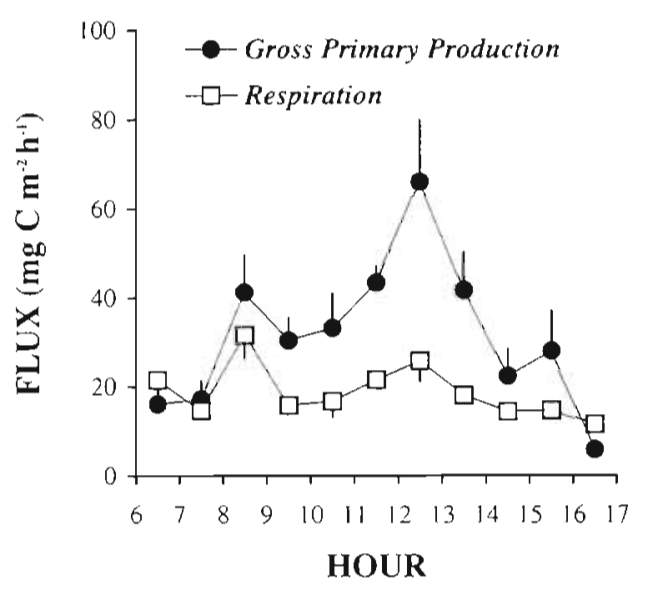

Fig. 3. Benthic gross primary production and respiration during the day. Vertical bars correspond to the standard errors

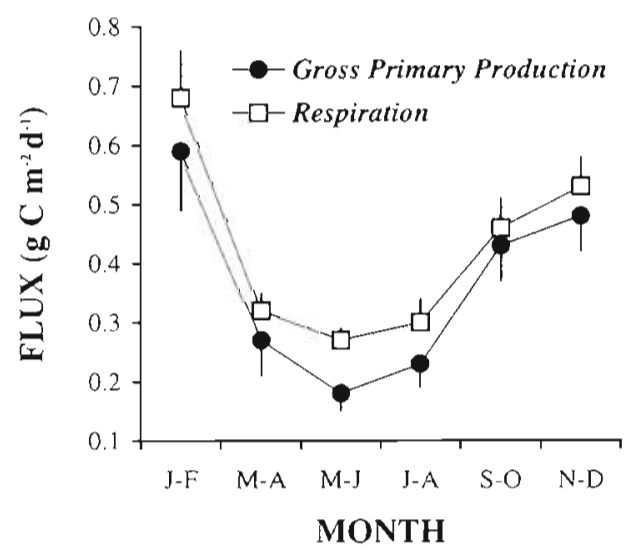

Fig. 4. Benthic gross primary production and respiration over the year. Vertical bars correspond to the standard errors

equivalent was $1.56 \mathrm{mmol} \mathrm{m} \mathrm{m}^{-2} \mathrm{~h}^{-1}$. The daily respiration was therefore $37.52 \mathrm{mmol} \mathrm{C} \mathrm{m}^{-2} \mathrm{~d}^{-1}(\mathrm{SE}=2.02)$, corresponding to an annual rate of $13.69 \mathrm{~mol} \mathrm{C} \mathrm{m}^{-2} \mathrm{yr}^{-1}$. The annual benthic respiration was $2.74 \times 10^{10} \mathrm{~mol} \mathrm{C} \mathrm{yr}^{-1}$ $\left(\mathrm{SE}=0.11 \times 10^{10}\right)$ for all sediments of the lagoon. The 3 replicate samples were not significantly different $(\mathrm{p}=$ 0.51 ) but the hypothesis of respiration homogeneity between stations can be rejected $(p<0.001)$. The distribution was similar to $P_{g}$, with similar values for the grey and the white sand bottoms and a significantly lower respiration for the muddy bottoms (Table 3 ). Respiration varied significantly (ANOVA, $p<0.01$ ) over the day (Fig. 3), with peaks at 8 to $9 \mathrm{~h}$ and 12 to $13 \mathrm{~h}$, but no clear pattern emerged. $P_{\mathrm{g}}$ exceeded respiration, and $P_{\mathrm{n}}$ was $>0$, from 8 to $16 \mathrm{~h}$. In contrast, a clear seasonal respiration cycle, similar to that of $P_{\mathrm{g}}$ can be observed (Fig. 4). In fact, the similarity of trends in $P_{\mathrm{g}}$ and respiration during the day and the year suggests a close coupling between these 2 parameters. This hypothesis is 


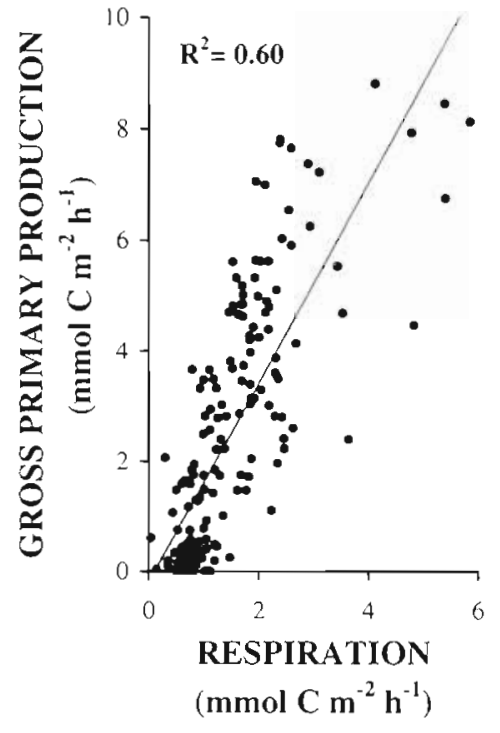

Fig. 5. Relationship between gross primary production and benthic respiration. The number of observations is 170

supported by the significant correlation $\left(R^{2}=0.66\right)$ between the 2 variables on the whole data set (Fig. 5).

\section{Production/respiration ratio and net photosynthetic production}

The $P_{g} / R$ ratio was 0.88 for the whole lagoon, with $95 \%$ confidence limits of 0.63 and 1.12. Mean $P_{\mathrm{g}} / R$ ratios varied monthly from 0.66 to 0.99 (Fig. 6). Lower values were observed from May to September, during the cool season, while the ratios were higher from October to February, indicating the importance of $P_{\mathrm{g}}$ during the warm season. This general feature was the result of different contributions from the 3 bottom types (Table 3 ). Highest $P_{\mathrm{g}} / R$ were observed for the grey and the white sand bottoms, whereas, respiration greatly exceeded $P_{\mathrm{g}}$ in muddy bottoms. The $P_{\mathrm{g}} / R$ ratio of muddy bottoms was the only one that was significantly different from 1 ( $p<0.05$ ). If one considers the area covered by each bottom type, $65 \%$ of the southwest lagoon of New Caledonia can be regarded as autotrophic, whereas $35 \%$ is markedly heterotrophic, leading to an annual carbon deficit greater than $3.5 \times$ $10^{9} \mathrm{~mol} \mathrm{C} \mathrm{yr}^{-1}$ (Table 4 ).

\section{Modelling of primary production}

Factors affecting primary production, irradiance (I) and plant biomass (Macroflora AFDW and chl a) were investigated. Values of regressions between these parameters are given in Table 5 . The bulk of gross pri-

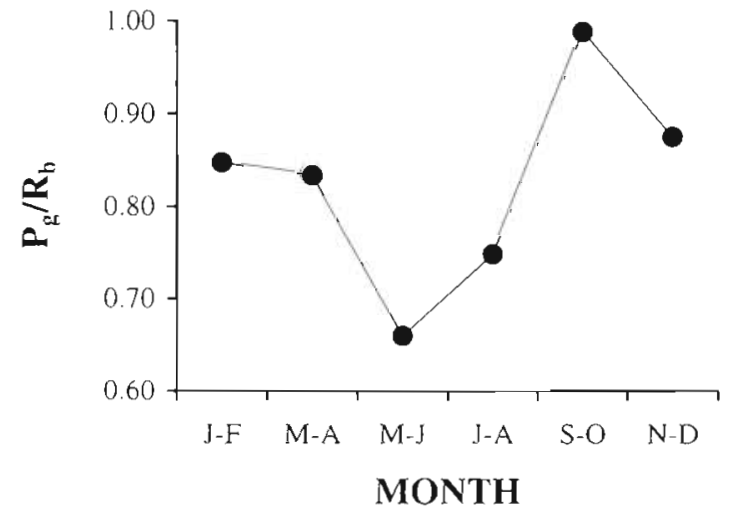

Fig. 6. The ratio of gross primary production $\left(P_{g)}\right.$ to respiration $(R)$ over the year

mary production variance was explained by light (Fig. 7). Contributions of $\mathrm{chl} a$ in the first $\mathrm{cm}$ of sediment and macrophyte biomass were less important. A general model including the 3 parameters has been adjusted to data. The equation for gross primary production is expressed as:

$$
\begin{aligned}
& P_{g}=5.84[1-\exp (-I / 319.73)] \\
& +0.04 \text { Macroflora AFD }+0.01 \text { chl } a-0.44
\end{aligned}
$$

This model, based upon 150 observations, explains $81 \%$ of gross primary production variance (Fig. 8). The relatively small increase in precision, compared to the $P_{g}$-light relationship $\left(R^{2}=0.72\right)$, is the result of significant correlation between light and both macrophyte biomass ( $\mathrm{r}=0.23, \mathrm{p}<0.01)$ and $\mathrm{chl} a(\mathrm{r}=0.43, \mathrm{p}<0.01)$.

Temperature is often an important causal factor in the variation of primary production in sediment areas (Moriarty et al, 1990). However, in this study, temperature only explains $4 \%$ of $P_{\mathrm{g}}$ and less than $1 \%$ of $R$ variance and we do not consider this parameter for modelling.

\section{DISCUSSION}

Benthic metabolism is seldom assessed on large spatial and temporal scales. Fluxes at the water-sediment

Table 4. Estimates (SE are in parentheses) of annual primary production $\left(P_{\mathrm{g}}\right)$, benthic respiration $(R)$ and net photosynthetic production $\left(P_{\mathrm{n}}\right)$, in $\times 10^{10} \mathrm{~mol} \mathrm{C} \mathrm{yr}^{-1}$ Area is expressed in $\mathrm{km}^{2}$

\begin{tabular}{|lrccr|}
\hline Bottom & Area & $P_{\mathrm{g}}$ & $R$ & \multicolumn{1}{c|}{$P_{\mathrm{n}}$} \\
\hline Mud deposits & 700 & $0.20(0.02)$ & $0.50(0.01)$ & $-0.30(0.03)$ \\
Grey sand & 1000 & $1.64(0.08)$ & $1.74(0.05)$ & $-0.10(0.09)$ \\
White sand & 300 & $0.55(0.02)$ & $0.50(0.05)$ & $0.05(0.03)$ \\
Whole lagoon & 2000 & $2.38(0.13)$ & $2.74(0.11)$ & $-0.35(0.15)$ \\
\hline
\end{tabular}


Table 5. Values of parameters (SE are in parentheses) calculated by regressions of gross primary production $\left(P_{g}\right.$, in $m m o l$ $\left.\mathrm{m}^{-2} \mathrm{~h}^{-1}\right)$ on light $\left(I, \mathrm{mmol} \mathrm{m}^{-2} \mathrm{~h}^{-1}\right)$, Macroflora ashfree dry weight (AFDW) $\left(\mathrm{g} \mathrm{m}^{-2}\right)$ and chl a (mg $\left.\mathrm{m}^{-2}\right)$. N: number of observations; $\mathrm{R}^{2}$ proportion of variance explained by the regression

\begin{tabular}{|c|c|c|c|}
\hline Adjusted model & Estimated parameters & $N$ & $\mathrm{R}^{2}$ \\
\hline$P_{\mathrm{g}}=P_{\max }\left[1-\exp \left(-L / I_{k}\right)\right]+e$ & $P_{\text {max }}=6.25(0.46), I_{k}=226.87(4.5 .7), e=-0.09(0.21)$ & 153 & 0.72 \\
\hline$P_{\mathrm{g}}=a_{1} \mathrm{chl} a+b_{1}$ & $a_{1}=0.05(0.01), b_{1}=0.36(0.30)$ & 170 & 0.30 \\
\hline$P_{\mathrm{g}}=a_{2}$ Macroflora AFDW $+b_{2}$ & $a_{2}=0.05(0.01), b_{2}=2.01(0.17)$ & 167 & 0.24 \\
\hline
\end{tabular}

interface are mainly derived from small-scale experiments in time or space, and, as already established for coral communities (Pichon 1997), generalisation of such data may hinder a realistic view of the complexity of nature. Benthic biomass and activity display large spatial and temporal heterogeneity; careful sampling is therefore required to derive reliable estimates of global metabolic parameters. Several assumptions are often made. Benthic respiration is generally considered as constant during a $24 \mathrm{~h}$ period and only varies with space and season. Primary production, in contrast, depends on irradiance and also varies according to the time of day. Benthic metabolism variation is sometimes considered in space only (Boucher et al. 1994a), or extrapolated using relationships established from partial sampling (Charpy-Roubaud 1988) of the survey area. In this study, we tried to enhance the accuracy of metabolic estimates by using a sampling design which takes into account the main factors influencing benthic metabolism (Rizzo \& Wetzel 1985).

The use of metabolic coefficients to calculate carbon fluxes from differences in oxygen concentration is a limitation of our method. The validity of community metabolic coefficients has been discussed by Clavier et al. (1994), and they are assumed to be representative of

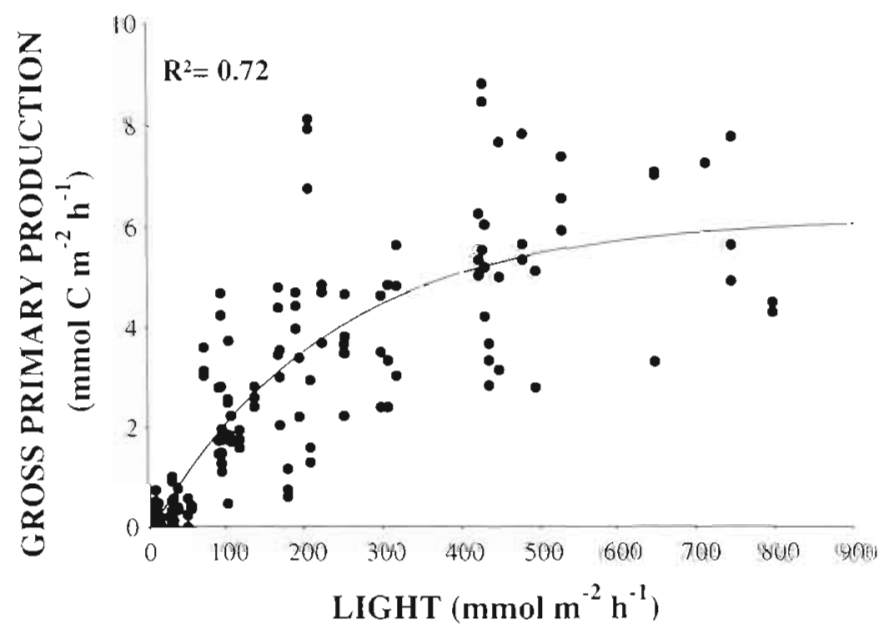

Fig. 7. Benthic gross primary production as a function of irradiance measured at the sediment surface the south-west lagoon of New Caledonia. CRQ and $C P Q$ are, however, only estimates of the lagoon characteristics and they explain 84 and $91 \%$ of the variance respectively. Variability of metabolic fluxes are thus underestimated in the present study. Other limitations of metabolic estimates are the necessity to extrapolate daytime values over the $24 \mathrm{~h}$ period and the fact that it is impossible to directly measure daytime respiration (Sournia 1977, Sorokin 1993). We postulated that day and night community respiration are equivalent at the same location and only vary seasonally and geographically in the lagoon. This hypothesis is obviously a simplification of natural processes (Revsbech et al. 1981, Lindeboom et al. 1985, Epping \& Jørgensen 1996) enhanced by the use of DCMU in a clear environment (Boucher et al. 1998). The spatio-temporal random sampling we used allows respiration fluctuation during daytime to be smoothed, and global estimations of $P_{\mathrm{g}}$ are not biased by $R$ fluctuations. In contrast, the extrapolation of $R$ over $24 \mathrm{~h}$ periods remains uncertain and further information on dark respiration is required. In the lagoon under study, evolution of

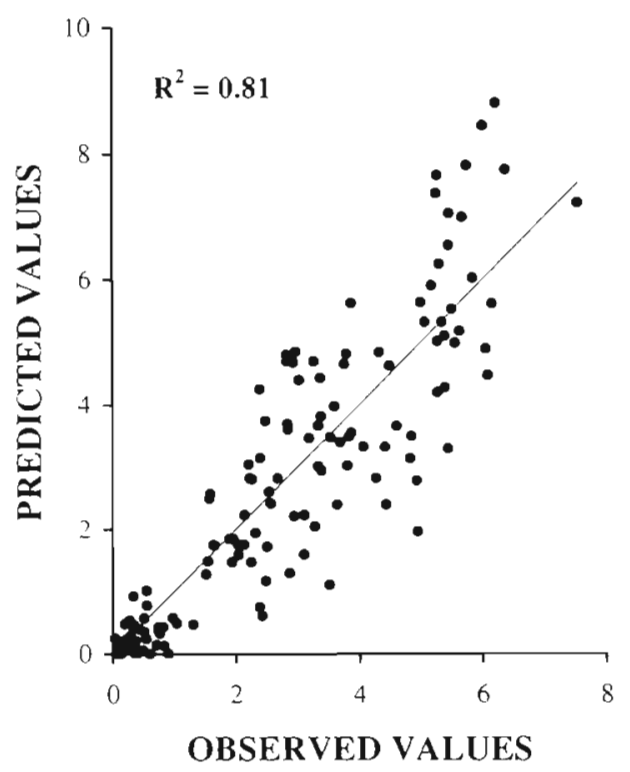

Fig. 8. Relationship between observed and predicted values of gross primary production in $\mathrm{mmol} \mathrm{C} \mathrm{m}^{-2} \mathrm{~h}^{-1}$ 
respiration during daytime is similar to $P_{\mathrm{g}}$ evolution, but with a lower variation range. This close relationship suggests a very fast mineralisation of a part of plant material by micro-organisms (Boucher \& Clavier 1990). Respiration might thus be lower at night than during the day (Revsbech et al. 1981). Our calculations of $24 \mathrm{~h}$ respiration are, therefore, too high; actual $P_{\mathrm{g}} / R$ ratios may be higher than our estimates, thus increasing the autotrophic character of sandy bottom benthic communities.

Sediments have received less attention than coral reef/flats (Gattuso et al. 1998). The reef environment is among the most productive ecosystems of the planet (Sorokin 1993); in contrast, adjacent lagoon sediments are regarded as of minor importance. In fact, besides the production per unit of surface, we have to consider the relative size of both systems. The highly productive reef flat corals are generally restricted to narrow reefs lining sometimes vast sediment areas. The south-west lagoon of New Caledonia is a good model of such a distribution, with a ratio of sediment to coral reef surface around 20 (Chardy et al. 1988). The actual reef production is still unknown in New Caledonia. However, if we accept that the order of magnitude matches the 'standard' reef flats, average value of ca $210 \mathrm{~mol}$ $\mathrm{C} \mathrm{m}{ }^{-2} \mathrm{yr}^{-1}$ (Kinsey 1985a), the sediment $P_{\mathrm{g}}$ value is about 20 times lower. This ratio is in agreement with the review of coastal ecosystem metabolism by Gattuso et al. (1998), with a $P_{\mathrm{g}}$ ranging from 30 to $1369 \mathrm{~mol} \mathrm{C}$ $\mathrm{m}^{-2} \mathrm{yr}^{-1}$ and from 8 to $82 \mathrm{~mol} \mathrm{C} \mathrm{m}{ }^{-2} \mathrm{yr}^{-1}$ for algal-dominated reef communities and sediments, respectively. At the whole reef ecosystem scale, coral reef and sediment production are therefore equivalent in the studied area. Comparison of $P_{\mathrm{g}}$ with other data is difficult because of different study scales and water depth. The importance of sedimentary processes in whole reef metabolism decreases as a function of depth. For example, sedimentary areas cover 40 to $60 \%$ of the Tiuahura reef flat surface (French Polynesia) and accounted for 3 to $30 \%$ of organic carbon excess production (Boucher et al. 1998). Our estimate is 1.6 times higher than that obtained by Charpy-Roubaud (1988) in the Tikehau lagoon with a similar mean depth (25.2 m). It is interesting to note that estimated production in the New Caledonia lagoon $\left(12 \pm 2 \mathrm{~mol} \mathrm{C} \mathrm{m}{ }^{-2} \mathrm{yr}^{-1}, 95 \%\right.$ confidence level) is similar to the average annual production (11 \pm $5 \mathrm{~mol} \mathrm{C} \mathrm{m}^{-2} \mathrm{yr}^{-1}$ ) calculated from a large set of studies considering various habitat, substrate type and latitude by Rizzo \& Wetzel (1985).

The estimated $P_{\mathrm{g}} / R$ ratio suggests that the whole south west lagoon of New Caledonia is heterotrophic. This lagoon harbours distinct environments and communities. Consequently, as already observed by Shaffer \& Onuf (1983) in a Southern Californian lagoon, global metabolic estimates result from the specific con- tributions of the different communities. Benthic metabolism is different in the 3 bottom types described in the lagoon (Chardy et al. 1988), with maximum production near the reef and minimum production on muddy sediments. In fact, 2 major bottom groups may be distinguished. Significantly heterotrophic sediments with low metabolic fluxes correspond to mud deposits (see Alongi 1990) near the coast and in the deeper parts of the lagoon. These sediments are located in zones with low residual velocity of tidal currents (Douillet 1998) and are the main site in which particulate organic carbon deposition occurs (Clavier et al. 1995). They also exhibit the lowest macro- and microphyte biomasses. In contrast, grey and white sand bottoms are autotrophic, with $P_{\mathrm{g}} / R$ ratios equal to or greater than 1 . They are, therefore, similar to the lagoon of French Frigate Shoals in Hawaii, where the mean $P / R$ ratio was 1.09 (Atkinson \& Grigg 1984). Grey and white sand bottoms develop where current velocities are relatively high, carrying away small sediment particles though the passes (Douillet 1998). In these communities with high plant biomass, the bulk of primary production is used for local metabolism (Lindeboom \& Sandee 1989, Moriarty et al. 1990). Macrophyte biomass is maximal on grey sand bottoms, while chl a concentrations are similar in both communities. We suppose that irradiance in shallower white sand bottoms balances the macrophyte deficit to give similar primary production for the 2 bottom types. Biomass of Sargassaceae may be abundant on a seasonal basis on back reef white sand bottom (Garrigue 1995). These algae are too large to be enclosed in the chambers that we used. Therefore, both biomass and production of white sand communities were underestimated. In brief, we observed that production increased from the relatively deep and turbid coastal waters to the shallow back reef sediments overlaid with clear oceanic waters flowing above the reef. This feature corresponds to a gradient in the ratio of terrestrial to oceanic influence, with allochthonous particulate carbon replacing autochthonous primary production near the shore (Clavier et al. 1995). The gradient is generated by water movement that is the driving mechanism for transporting terrestrial inputs. Hydrodynamics is, therefore, the major factor influencing spatial distribution of benthic metabolism in the lagoon (see also Lewis et al. 1985). It determines, though turbidity, the irradiance on the sea floor, and influences the quantity of fine particles in the sediment, thereby controlling benthic community composition.

In the study area, benthic metabolism shows a clear seasonal trend with about a 3 -fold variation thoughout the year. Maximum values are observed from November to February, during the warm season, when water temperatures exceed $25^{\circ} \mathrm{C}$. In contrast, metabolism is 
markedly lower from April to September, during the cool season, with relatively lower temperatures $\left(<25^{\circ} \mathrm{C}\right)$. A similar temporal course of metabolism has already been described by Kinsey (1985b), Klumpp \& McKinnon (1989), Hansen et al. (1992) and Uthicke \& Klumpp (1998) in Australia. Unlike Grant's (1986) findings in a temperate ecosystem, temperature is not the main cause of seasonal cycle in the lagoon benthic metabolism; it depends, rather, on light availability (Yap et al. 1994) and plant biomass. In New Caledonia, irradiance is maximum between October and December and minimum in June (Anonymous 1981). Similar seasonal variations are observed for micro- and macroflora biomasses and macroflora production (Garrigue 1991) with significantly higher values in JanuaryFebruary. Fluctuation of the New Caledonia climate between a warm and a cool season has, therefore, some relevance to benthic metabolism. The warm season is also the period of maximum runoff associated with the main rainfall season, whereas river water levels are lowest during the cool season. Material carried by rivers towards the lagoon causes a rise in suspended material concentration and a related increase in particulate matter sedimentation (Clavier et al. 1995). The terrestrial influence gradient is most extreme during the warm season when benthic primary production is limited in mud deposits, but minor influence is exerted on back-reef communities due to the large distance $(>10 \mathrm{~km})$ across the lagoon. Seasonal fluctuation of light related to solar illumination, or to variations in water turbidity, is likely to reinforce the spatial gradient observed in the lagoon.

If $P_{\mathrm{g}} / R$ varies on a spatial basis, a close relationship is observed between benthic production and respiration at different periods of the year. $P_{\mathrm{g}}$ is essentially related to irradiance and plant biomass, but $R$ is a more complex indication of benthic energy demand. The latter is detritus based (Chardy \& Clavier 1988b, Alongi 1989) and fuelled by autochthonous primary production and by allochthonous carbon sedimented from the water column (Hansen et al. 1992). In the south-west lagoon of New Caledonia, organic matter originating from seston has a high $\mathrm{C} / \mathrm{N}$ ratio indicating its refractory nature (Clavier et al. 1995), in contrast to benthic plant material which is more labile. The total lagoon is, however, heterotrophic and depends on the seasonal supply of particulate organic matter (Clavier et al. 1995), with maximum organic carbon sedimentation from February to June, medium sedimentation in November, and minimum from July to October. The seasonal cycle of $P_{\mathrm{g}} / R$ reflects this input, with decreasing values during the high sedimentation period and a rise after June, with enhancement of the relative amount of energetic autochthonous organic matter. Our data support and generalise the findings of Hansen et al. (1992) in Davies Reef lagoon. A similar variation in $\mathrm{P}_{\mathrm{g}} / \mathrm{R}$ ratio was also found by Hopkinson (1985) in an heterotrophic temperate environment where organic matter that sustain the metabolic activity varied in quality and quantity

The present study suggests that soft bottoms of the New Caledonia south-west lagoon are important sites of organic matter production and decomposition. Overall, the lagoon benthos is heterotrophic because of the carbon deficit of coastal and deep muddy bottoms. Carbon production balances respiration demand, however, in about two-thirds of the area of the bottom. This feature suggests that the autotrophic character of coral reef ecosystems (Gattuso et al. 1998) is also characteristic of nearby sediments, indicating both a major importance of regeneration processes and a relative equilibrium of energy exchanges with adjacent ecosystems. Terrestrial influence on such a reef ecosystem leads to a decrease of autochthonous production and a correlated increase of carbon sedimentation leading to benthic heterotrophy.

Acknowledgements. We gratefully acknowledge the crew of the RV 'Alis' for their help at sea. We thank G. Bargibant, P. Hamel, J. L. Menou and P. Tirard for their help in diving, and A. Di Matteo for laboratory assistance. We are particularly indebted to J. Y. Panché, for his invaluable assistance with the electronic equipment. This study was supported by the ORSTOM 'Lagon' program.

\section{LITERATURE CITED}

Alongi DM (1989) The role of soft-bottom benthic communities in tropical mangrove and coral reef ecosystems. CRC Crit Rev Aquat Sci 1:243-280

Alongi DM (1990) The ecology of tropical soft-bottom benthic ecosystems. Oceanogr Mar Biol Annu Rev 28:381-496

Alongi DM, Chistoffersen P (1992) Benthic infauna and organism-sediment relations in a shallow, tropical area: influence of outwelled mangrove detritus and physical disturbance. Mar Ecol Prog Ser 81:229-245

Anonymous (1981) Eléments généraux du climat. In: Saulter $G$ (ed) Atlas de Nouvelle-Calédonie et Dépendances. ORSTOM, Paris, p 1-11

Atkinson MJ, Grigg R (1984) Model of a coral reef ecosystem. II. Gross and net benthic primary production at French Frigate Shoals, Hawaii. Coral Reefs 3:13-22

Boucher G, Boucher-Rodoni R (1985) Fluctuations des nutriments au cours de la marée sur les parcs ostréicoles de la Rivière Penzé (Nord Finistère). Hydrobiologia 123: 251-261

Boucher G, Boucher-Rodoni R (1988) In situ measurement of respiratory metabolism and nitrogen fluxes at the interface of oyster beds. Mar Ecol Prog Ser 44:229-238

Boucher G, Clavier J (1990) Contribution of benthic biomass to overall metabolism in New Caledonia lagoon sediments. Mar Ecol Prog Ser 64:271-280

Boucher G, Clavier J, Garrigue C (1994a) Oxygen and carbon dioxide fluxes at the water-sediment interface of a tropical lagoon. Mar Ecol Prog Ser 107:185-193

Boucher G, Clavier J Garrigue C (1994b) Estimation of ammo- 
nium affinity in the New Caledonia lagoon. Coral Reefs $13: 13-19$

Boucher G, Clavier J, Gattuso JP (1998) Contribution of softbottoms to the community metabolism (carbon production and calcification) of a barrier reef flat (Moorea, French Polynesia). J Exp Mar Biol Ecol 225:269-283

Chardy P, Clavier J (1988a) Biomass and trophic structure of the macrobenthos in the south-west lagoon of New Caledonia. Mar Biol 99:195-202

Chardy P, Clavier J (1988b) An attempt to estimate the carbon budget for the south-west lagoon of New Caledonia. Proc 6th Int Coral Reef Symp. Townsville 2:541-546

Chardy P. Chevillon C. Clavier J (1988) Major benthic communities of the south-west lagoon of New Caledonia. Coral Reefs 7:69-75

Charpy-Roubaud C (1988) Production primaire des fonds meubles du lagon de Tikehau (atoll des Tuamotu, Polynésie française). Oceanol Acta 11:241-248

Clavier J, Boucher G, Garrigue C (1994) Benthic respiratory and photosynthetic quotients in a tropical lagoon. CR Acad Sci Paris 317:937-942

Clavier J, Chardy P, Chevillon C (1995) Spatial and temporal patterns of particulate matter sedimentation in the SW lagoon of New Caledonia. Estuar Coast Shelf Sci 40 $281-294$

Cochran WG (1977) Sampling techniques. John Wiley \& Sons, New York

Crossland CJ, Hatcher BG, Smith SV (1991) The role of coral reefs in global carbon production. Coral Reefs 10:55--64

Douillet P (1998) Tidal dynamics of the south-west lagoon of New Caledonia: observations and 2D numerical modelling. Oceanol Acta 21:69-79

Dromgoole FI (1978) The effect of oxygen on dark respiration and apparent photosynthesis of marine macro-algae Aquat Bot 4:281-297

Dubinsky Z (ed) (1990) Coral Reefs. Elsevier, New York

Epping EHG, Jorgensen BB (1996) Light-enhanced oxygen respiration in benthic phototrophic communities. Mar Ecol Prog Ser 139:193-203

Folk RLW, Ward WC (1957) Brazos river bar: a study of significance of grain size parameters. J Sediment Petrol 24:3-26

Forja JM, Gómez-Parra A (1998) Measuring nutrient fluxes across the sediment-water interface with benthic chambers. Mar Ecol Prog Ser 164:95-105

Garrigue C (1991) Biomass and production of two Halimeda species in the Southwest New Caledonia lagoon. Oceanol Acta 14:581-588

Garrigue C (1995) Macrophyte associations on the soft bottom of the south-west lagoon of New Caledonia. Bot Mar 38 $481-492$

Garrigue C (1998) Distribution and biomass of microphytes measured by benthic chlorophyl] a in a tropical lagoon (New Caledonia, South Pacific). Hydrobiologia 385:1-10

Garrigue C, Di Matteo A (1991) La biomasse végétale benthique du lagon sud-ouest de Nouvelle-Calédonie. Résultats bruts: liste taxonomique, biomasses, pigments chlorophylliens. Arch, Sci Mer, Biol Mar, ORSTOM, Nouméa

Garrigue C, Clavier J, Boucher G (1992a) The use of photosynthesis inhibrtor (DCMU) for in situ metabolic and primary production studies on soft bottom benthos. Hydrobiologia 246:141-145

Garrigue C, Clavier J, Bargibant G, Di Matteo A, Hamel P, Menou JL, Panche JY, Tirard P (1992b) Production primaire du lagon sud-ouest de Nouvelle-Calédonie: methodes et recueil des données. Rapp Sci Tech, Sci Mer, Biol Mar, ORSTOM, Nouméa

Gattuso JP, Pichon M, Delessalle B, Frankignoulle M (1993)
Community metabolism and air-sea $\mathrm{CO}_{2}$ fluxes in a coral reef ecosystem (Moorea, French Polynesia). Mar Ecol Prog Ser 96:259-267

Gattuso JP, Pichon M, Delesalle B, Canon C, Frankignoulle $M$ (1996) Carbon fluxes in coral reefs. I. Lagrangian measurement of community metabolism and resulting air-sea $\mathrm{CO}_{2}$ desiquilibrium. Mar Ecol Prog Ser 145:109-121

Gattuso JP, Frankignoulle M. Wollast R (1998) Carbon and carbonate metabolism in coastal aquatic ecosystems Annu Rev Ecol Syst 29:405-434

Grant J (1986) Sensitivity of benthic community respiration and primary production to changes in temperature and light. Mar Biol 90:299-306

Hansen JA, Klumpp DW, Alongi DM, Dayton PK, Riddle MJ (1992) Detrital pathways in a coral reef lagoon. II. Detritus deposition, benthic microbial biomass and production. Mar Biol 113:363-372

Hopkinson CS Jr (1985) Shallow-water benthic and pelagic metabolism: evidence of heterotrophy in the nearshore Georgia Bight. Mar Biol 87:19-32

Kinsey DW (1985a) Metabolism, calcification and carbon production. I. Systems level studies. Proc 5th Int Coral Reef Cong 4:505-526

Kinsey DW (1985b) The functional role of back-reef and lagoonal systems in the central Great Barrier Reef. Proc 5th Int Coral Reef Cong 6:223-228

Klumpp DW, McKinnon AD (1989) Temporal and spatial patterns in primary production of a coral-reef epilithic algal community. J Exp Mar Biol Ecol 131:1-22

Lewis JB, Gladfelter EH, Kinsey DW (1985) Metabolism, calcification and carbon production. III. Seminar discussion. Proc 5th Int Coral Reef Cong 4:540-542

Lindeboom HJ, Sandee AJJ (1989) production and consumption of tropical seagrass fields in eastern Indonesia measured with bell jars and microelectrodes. Neth J Sea Res 23:181-190

Lindeboom HJ, Sandee AJJ, de Klerk-Van den Driessche HAJ (1985) A new bell jar/microelectrode method to measure changing oxygen fluxes in illuminated sediments with microalgal cover. Limnol Oceanogr 30:693-698

Lorenzen CJ (1967) Determination of chl and pheopigments: spectophotometric equations. Limnol Oceanogr 12:343-346

Moriarty DJW, Roberts DG, Pollard PC (1990) Primary and bacterial productivity of tropical seagrass communities in the Gulf of Carpentaria, Australia. Mar Ecol Prog Ser 61 . $145-157$

Patterson MR, Sebens KP, Olson RR (1991) In situ measurements of flow effects on primary production and dark respiration in reef corals. Limnol Oceanogr 36:936-948

Pichon M (1997) Coral reef metabolism in the Indo-Pacific: the broader picture. Proc 8th Int Coral Reef Symp 1:977-980

Revsbech NP. Jørgensen BB, Brix O (1981) Primary production of microalgae in sediments measured by oxygen microprofile, $\mathrm{H}^{14} \mathrm{CO}_{3}^{-}$fixation, and oxygen exchange methods. Limnol Oceanogr 26:717-730

Richer de Forges B (1991) Les fonds meubles des lagons de Nouvelle-Calédonie. Etudes et Thèses. ORSTOM, Paris

Rizzo WM, Wetzel RL (1985) Intertidal and shoal benthic community metabolism in a temperate estuary: studies of spatial and temporal scales of variability. Estuaries 8: $342-351$

Shaffer GP, Onuf CP (1983) An analysis of factors influencing the prumary production of the benthic microflora in a southern California lagoon. Neth J Sea Res 17:126-144

Smith SV (1995) Reflections on the measurement and significance of carbon metabolism on coral reefs. Kans Geol Survey Open-File Rep Ser 95-96a:1-18 
Sokal RR, Rohlf FJ (1981) Biometry. Freeman and Company, New York

Sorokin YI (1993) Coral reef ecology. Springer Verlag, Berlin Sournia A (1977) Analyse et bilan de la production primaire dans les récifs coralliens. Ann Inst Océanogr, Paris 53:47-74

Uthicke S, Klumpp DW (1998) Microphytobenthos community production at a near-shore coral reef: seasonal varia-

Editorial responsibility: Otto Kinne (Editor),

Oldendorf/Luhe, Germany tion and response to ammonium recycled by holothurians. Mar Ecol Prog Ser 169:1-11

Wentworth CK (1922) A scale of grade and class terms for clastic sediments. J Geol 30:377-392

Yap HT, Montebon ARF, Dizon RM (1994) Energy flow and seasonality in a tropical coral reef flat. Mar Ecol Prog Ser $103: 35-43$

Submitted: March 11, 1999; Accepted: July 16, 1999 Proofs received from author(s): December 12, 1999 